\title{
The effect of risk reduction strategies on operational performance of telecommunication companies in Rwanda
}

\author{
Ingabire Anitha ${ }^{1}$ and Njenga Gitahi Samson ${ }^{2}$ \\ ${ }^{1}$ School of Business and economics, Mount Kenya University, \\ Kigali, Rwanda
}

\begin{abstract}
The purpose of this articlewas to determine the effect of risk reduction strategies on operational performance of telecommunication companies in Rwanda after merging. The article adopted value creation theory and agency theory. The article used descriptive research design with a correlation regression size effect. The population consisted of 118 managerial staff at Airtel Rwanda since they understand the effect of the mergers and acquisitions as a growth strategy. A sample size of 91 respondents was selected for the study. This study used primary and secondary data collection methods. Primary data was collected using a survey questionnaire while secondary data were sources from published and unpublished sources from the merged companies. Data was analyzed using descriptive statistics in frequencies, percentages, standard deviations, and means. Inferential statistics was used during analysis. The findings showed that during the merger and acquisition risk reduction occurred to some extent and after the M\&A Airtel's performance improved. Positive correlation was found between culture evaluation and flexibility( $\mathrm{r}=231^{* *}, \mathrm{p}=0.006$ ), culture evaluation and product quality $\left(\mathrm{r}=.159^{* *}, \mathrm{p}=0.043\right.$, culture evaluation and customer trust $\quad(\mathrm{r}=.174 * *=0.014)$. Results demonstrated that a positive correlation between retention strategy and flexibility ( $\mathrm{r}=.274 * *$, $\mathrm{p}=0.039$ ), retention strategy and product quality $(\mathrm{r}=.187, \mathrm{p}=0.035)$ retention strategy and customer trust $(\mathrm{r}=.324, \mathrm{p}=0.032)$
\end{abstract}

\section{Introduction}

Globalization has become the force behind the need for companies to seek strategies of expanding their operations and also to become more efficient ( $\mathrm{Al}-$ hroot,2016). On the other hand, the fierce competition that characterizes the global market requires that companies have to develop some competitive advantage that can propel them ahead of the other competitors. One of the strategies that most companies adopt to gain competitive advantage is through mergers and acquisitions (M\&A). The fundamental objective of M\&A is to provide strong company capability of meeting customer satisfaction, and also to reduce fierce competition and evolve into technological development that will enhance better performance and realization of substantial profits (Boukari \& Xiaofang, 2014)

Mergers and acquisitions ( $M$ \& As) are corporate restructuring activities conducted in a bid to enhance the firms' returns or increase the efficiency of their operations. There are enormous benefits attributed to M\&As and this factor has increased their attractiveness globally hence the recent trend towards M\&As. Generally, merging firms operate in the same industry or under same market conditions and structures (Kamau, 2014). Firms that go through M\&A enjoy a number of benefits (Carriquiry,2017) indicates that M\&A enable firms to enjoy cost savings. The firms are able to incur fewer costs in their activities due to the economies of scale enjoyed. $\mathrm{He}$ also argues that by increasing its size through mergers and acquisitions, a firm has the potential of increasing its buyer power that will enable it enjoy huge discounts. M\&A enable firms to grow and expand their territory which enables them to enjoy greater control of the market within which they operate (Kim, Haleblian, \& Finkelstein, 2011)

The Airtel -Tigo Rwanda merger and acquisition was finalized in 2018 with Airtel in hoping to acquire the already large market of Tigo, its Network infrastructure and employees. Though the merger did increase the market share of Airtel, a number of employees were laid off and these did have significant personal customers around Rwanda. The merge was made upon promises of better service to the client. However to date there have been few studies conducted to establish the effect of the M\&A on Airtel to show how its operations are performing. The key question that the researcher seeks to answer is what strategy Airtel used that would guarantee it achieved a better operational performance in the merger and acquisition process. 


\section{Review of Literature}

\subsection{Merger and Acquisition Strategies}

Mergers and acquisitions ( $M$ \& As) are corporate restructuring activities conducted in a bid to enhance the firms' returns or increase the efficiency of their operations (Ondieki \& Mungai, 2015). There are enormous benefits attributed to M\&As and this factor has increased their attractiveness globally hence the recent trend towards M\&As. Generally, merging firms operate in the same industry or under same market conditions and structures. Firms that go through M\&A enjoy a number of benefits. Leepsa and Mishra (2016) indicates that M\&A enable firms to enjoy cost savings. The firms are able to incur fewer costs in their activities due to the economies of scale enjoyed. He also argues that by increasing its size through mergers and acquisitions, a firm has the potential of increasing its buyer power that enables it enjoy huge discounts. M\&A enable firms to grow and expand their territory which enables them to enjoy greater control of the market within which they operate (Leepsa \& Mishra, 2016).

There are various theories that explain the motivation for M\&As as advanced by different finance and economics scholars as they aim to demystify the rationale for M\&As. This study has identified five theories behind M\&As. These include the theory of synergy, theory of economies, diversification effect theory, tax effect theory and disciplinary theory. In response to changes in the operating environment, various financial institutions such as insurance companies have merged or taken over other existing operations (acquisitions) (Hitt et al., 2012).

According to Essays (2018) M\&As are being increasingly used world over for improving competitiveness of companies through gaining greater market share, broadening the portfolio to reduce business risk for entering new markets and geographies, and capitalizing on economies of scale among others. The reasoning behind any corporate merger is that two companies are better than one because they increase shareholder value over and above that of the two separate firms. The motives behind M\&As are economies of scale, increase in market share and revenues, taxation, synergy, geographical and other diversification. Notwithstanding, achieving appraise beginning through M\&A is not always practicable. Indeed, a substantial harm to organizations' performance has been recorded due to M\&A. M\&A led to poor decision making in increased overhead costs after M\&A, agency problems and hubris point activity (Ondieki \& Mungai, 2015).

\section{Operational Integration Strategy}

The operational integration as coordination and control between the merging firms through organizational structures and systems, the aim of which is to create value by being able to reach organizational goals more effectively (Teixeira,

\section{ISSN 2455-6378}

Koufteros, Xiaosong, \& Peng, 2012). Depending on whether the acquisition was through absoption or symbiotic strategies, the perception of the individuals will highly determine how motivated they get to collaborate. Absorption acquisitions may require coercion and direct pressure on part or the acquirer, which reduces the individuals' motivation to collaborate (Teixeira et al., 2012) while Symbiosis acquisitions are likely to involve less coercive operational changes in a sense that they have to be "negotiated" and "reasoned" between the merger partners in order to decide how different organizational aspects are to be integrated, which is likely to create perceptions of procedural fairness amongst organizational members in the target firm (Teixeira et al., 2012) and, as a result, reduce the risk of disruptive political behavior.

\section{Cultural Integration Strategy}

Cultural integration: represents the ideological and human side of the integration process. Organizational cultural integration is the development of a common organizational culture with shared espoused values and belief systems (Teixeira et al., 2012). Organizational cultural integration can happen in teo ways namely; convergence or crossvergence. Convergence is whereby the acquiring firm demands that its culture is imposed over the target. In the case of crossvergence a new shared culture that is distinct from the previous cultures of both the acquiring and the target is created (Teixeira et al., 2012). Crossvergence is thus inherently a more mutual, collaborative process in which specific cultural characteristics of both partners are combined or entirely new cultural dimensions are created by introducing values and beliefs distinct from those of the acquirer and the target and specific for the new merged organization.

\section{Risk Reduction Strategy}

Managing risks is a major challenge that companies involved in mergers and acquisition have to deal with. According to survey conducted by KPMG in 1999 on mergers and acquisitions revealed that only 17 percent of the deals added value to the combined company, 30 percent produced no visible difference, and as many as 53 percent actually created negative value (Sciriha \& Debono, 2017).

The level of risk involved depends on the nature of the merger/acquisition. Factors capable of increasing the level of risk in a merger or acquisition between two companies include geographic locations of the companies, the disparity between their cultures, the level of divergence of their internal technological systems, the degree of disparity between their values and believe systems (Sciriha \& Debono, 2017). The over payment made by a company during an acquisition may be such that wipes out any future profitability potential the new entity possess (Bruno 
\& Broderick, 2014). There is a possibility that during a bidding process some of the bidders participating in the process may be doing so for various reasons. These bidders may make bids that are irrational thereby influencing other bidders to bid and eventually pay too high.Weber (2015) reports seven possible post-merger factors that cause mergers and acquisitions to fail and they include the following: The first factor is when the employees within the organisation get pre-occupied with activities that will bring no positive result to the merger process. During this period of uncertainty misinformation or lack of it get people confused and their productivity drop drastically. The second factor identified is list making. Departments and units within the organization all start clamouring for resources as soon as the merger is announced. Most people focus on the allocation of resources than the real value drivers and activities that will positively impact the growth of the company.

The third factor is organizational proliferation. It should be understood that the way one organisation sees things and operates might be different from another organisation especially if they are in different industries or countries. The organisation should therefore, focus a lot of attention in ensuring that people are adequately carried along and not left in the dark or to guessing. The fourth factor is infrequent and irrelevant communication. Top managers may shy away from passing information to employees, shareholders and customers for fear of not wanting to pass the wrong information. This lack of information may cause panic created out of the perceived vacuum. To curb this there must be clearly defined communication channels. The organisation involved should make deliberate effort to create good communication strategies. The fifth factor is triangulation. It is identified that managers and employees don't know who to report to and how they fit in during a merger. Some organisations are more rigid than others when it comes to following a defined organisational hierarchical structure. The sixth factor is the issue of time and space. Time is of the essence in every merger as all the stakeholders including shareholders; employees and customers expect quick improvement in performance within the period preceding the merger.The last factor focuses on ensuring there is strong and competent leadership. Employees need a visionary leader with sound character to lead them especially during and after mergers. They need to be guided and encouraged to remain focused and committed to the objectives of the new entity. The new leadership should be able to highlight and communicate clearly the reasons behind the merger and the benefit every stakeholder within the organisation is to gain as a result of the merger.

\section{ISSN 2455-6378}

\section{Operational Performance}

Operational performance refers to the measurable aspects of the outcomes of an organization's processes, such as reliability, production cycle time, and inventory turns. Operational performance in turn affects business performance measures such as market share and customer satisfaction ( Weber,2015). Operational performance is a firm's performance measured against a standard or prescribed indicator of effectiveness, efficiency and environmental responsibility such as cycle time, productivity, waste reduction and regulatory compliance. The major tasks that contribute to improvement of operational performance include procurement, new product development, production, marketing and logistics (Moore, 2011)When internal functions are integrated there is more cooperation in the organization and delivery of goods and services is affected as the elements of operational performance of cost, flexibility, and quality and delivery reliability are affected.

\section{Materials and Methods}

The study is a descriptive in nature and specifically correlative design. Correlation design is a nonexperimental research method in which two variables are measured because either the researcher believes their relationship is not a casual one and in this case neither one of the variables is manipulated by the researcher (Chiang et al., 2015). M\&A strategies on operational performance is a dynamic relationship in which an experiment would fail to control several factors. Statistically determining their relationship is most optimal and valid approach for this study.

\section{Target Population}

According to (Strydom, 2015)a population is a welldefined set of people, services, elements, and events, group of things or households that are being investigated. The target population of this study was Airtel Rwanda. The choice of Airtel Rwanda as the study unit was informed by its mergers with Tigo Rwanda in the recent past. The population consisted of 118 managerial staff at Airtel Rwanda since they understand the effect of the mergers and acquisitions as a growth strategy.

\section{Sample Design \\ Sample Size}

Creswell (2013) stated that, in purposive sampling, researchers intentionally select individuals and sites to learn or understand a phenomenon. For estimating this sample from population, the researcher used the following Yamane T. (1967) formula: $n=\frac{N}{1+N *(e)^{2}}$ Where $\mathrm{n}$ is the sample size, $\mathrm{N}$ is the total population and e is the error. According to Hussey and Hussey (1997) no survey can ever be deemed to be free from error or provide $100 \%$ surety and error limits of less 
than $10 \%$ and confidence levels of higher than $90 \%$ can be regarded as acceptable. By using the Yamane's formula of sample size with an error of $5 \%$ and with a confidence coefficient of $95 \%$;

$\frac{N}{1+N *(e)^{2}}=\frac{118}{1+118 *(0.05)^{2}}=91$

From the estimation, 91 participants were included in the study

\section{Sampling Techniques}

Sampling technique aims at eliminating biasness of selecting the sample from wider population. The sampling technique to be used was purposive sampling and simple random sampling

\section{Data Collection Methods}

This study used primary and secondary data collection methods. Primary data was collected using a survey questionnaire while secondary data was sources from published and unpublished sources from the merged companies.

\section{Data Collection Instruments}

\section{Table 4. 1 Gender of Respondents}

A self-administered survey questionnaire was used to collect information from the respondents. The research questionnaire had two sections. The first section recorded the demographic characteristics of respondents and the second section recorded responses in regards to the objectives in a prearranged order. A survey questionnaire is selected as the main data collection tool due to its ability to collect information in a timely manner. It is also easy to administer and analyze.

\section{Results and Discussion}

\subsection{Demographic Characteristics}

The demographic characteristics of respondents is very important in understanding how it can influence the effect of mergers and acquisitions on operational performance. The researcher sought to provide gender, age, marital status and education profile of respondents

\section{Gender of Respondents}

The Table provides a description of gender analysis of respondents

\begin{tabular}{lrr}
\hline Gender of Respondents & Frequency & Percent \\
\hline Male & 64 & 70.3 \\
Female & 27 & 29.7 \\
Total & $\mathbf{9 1}$ & $\mathbf{1 0 0 . 0}$ \\
\hline
\end{tabular}

\section{Source: Primary data (2021)}

The gender distribution of the sample is presented in Table 4.2. It shows that 64(70.3) where male while $27(29.7 \%)$ were female. The finding shows that majority of the respondents were male. These results on gender is associated with administered questionnaire to the respondents to ensure gender equality, therefore, the purpose of gender equity for this research was to establish different ideas and their importance to operational performance, the results in gender equality is relevant in this research for assessing their role in increasing operational performance.

\section{Working Experience}

The researcher sought to provide information on working experience in position in the organization for telecommunication companies in Rwanda. Results are presented in Table 4.2.

Table 4. 2 Worked with Tigo

\begin{tabular}{|c|c|c|}
\hline Working with Tigo & Frequency & Percent \\
\hline Yes & 34 & 37.4 \\
\hline No & 57 & 62.6 \\
\hline Total & 91 & 100.0 \\
\hline
\end{tabular}

Source: Primary data (2021)

Table 4.3 asked whether the respondent had worked in Tigo before the transfer to Airtel. Accordingly 34 (37.4\%) affirmed while 57(62.6\%) were new staff.
The finding shows that Airtel employed more staff than merge the Tigo staff. The sample shows over half of the staff where new staff. 
Results demonstrate that the turnover at company level isstable and have a sufficient working experience in strategy formulation, communication and execution, therefore its operational performance on flexibility, product quality and customer trust.

Table 4. 3 Education Level

\section{Education Level of Respondents}

The research sought to provide educational profile of respondents in order to ascertain if operational performance of telecommunication companies depends on skills and knowledge of employees in applying merger and acquisitions strategies.

\begin{tabular}{lrr}
\hline Education Level & Frequency & Percent \\
\hline Secondary & & 5.5 \\
Bachelor & & 74.7 \\
Masters & 68 & 19.8 \\
Total & 18 & $\mathbf{1 0 0 . 0}$ \\
\hline
\end{tabular}

Source: Primary data (2021)

The current staff is composed of $68(74.7 \%)$ Bachelor's degree holders and about $19.8 \%$ with master degree. The sample shows that the respondents were competent enough to provide the information required in the study.

Level of operational performance of telecommunication companies after merging

Table 4. 4 Level of operational performance
In Table 4.1 demonstrate a descriptive statistics of the dependent variable which is organizational performance of telecommunication companies after merging. The respondents were asked to demonstrate the level of organizational performance on flexibility, product quality, and customer trust. The range of respondents was strongly Agree (5) and strongly disagree (1).

\begin{tabular}{|c|c|c|c|c|c|c|c|c|c|c|c|c|c|}
\hline & \multicolumn{2}{|c|}{$\begin{array}{l}\text { Strongly } \\
\text { Disagree }\end{array}$} & \multicolumn{2}{|c|}{ Disagree } & \multicolumn{2}{|c|}{$\begin{array}{l}\text { Not } \\
\text { Sure }\end{array}$} & \multicolumn{2}{|c|}{ Agree } & \multicolumn{2}{|c|}{$\begin{array}{c}\text { Strongly } \\
\text { Agree }\end{array}$} & \multicolumn{3}{|c|}{ Total } \\
\hline & $\mathrm{N}$ & $\%$ & $\mathrm{~N}$ & $\%$ & $\mathrm{~N}$ & $\%$ & $\mathrm{~N}$ & $\%$ & $\mathrm{~N}$ & $\%$ & $\mathrm{~N}$ & Mean & Std \\
\hline Flexibility & 3 & 3.3 & 5 & 5.5 & 11 & 12.1 & 45 & 49.5 & 27 & 29.7 & 91 & 3.97 & .971 \\
\hline Product Quality & 5 & 5.5 & 2 & 2.2 & 7 & 7.7 & 54 & 59.3 & 23 & 25.3 & 91 & 3.92 & .959 \\
\hline Customer Trust & 3 & 3.3 & 9 & 9.9 & 20 & 22.0 & 38 & 41.8 & 21 & 23.1 & 91 & 3.71 & 1.03 \\
\hline
\end{tabular}

Source: Primary Data (2021)

According to the finding, the general response was that the flexibility was realized at Airtel Rwanda, $45(49.5 \%)$ and this was confirmed by respondents. It was also agreed that product quality was increased at Airtel, 54 (59.3\%). The general staff observed that Airtel has led to customer trust, 38 (41.8\%).

The finding shows that Airtel has become flexible but at varying levels. They developed products that respond to client demands, had mechanisms in place to meet the growing demand however there was a challenge on readiness to the response and suppliers too are slow in their response and not very open to new ideas. All these aspects of quality were confirmed by the former staff of Tigo. This implies that from their perspective Airtel has provided a different quality than that which they formerly experienced. The finding shows that quality of service and products improved in Airtel after merger and acquisition with more adherence to international standards, product and service variations, quality products, storage, control of tracking and suppliers. The finding indicates that Airtel has increased on customer trust after the merger and acquisition in partnership with customers, contracts, collaborations.

\subsection{Effect of Risk Reduction Strategy on Organizational Performance of Airtel-Tigo}

In order to determine the effect of risk reduction strategy on operational performance, it is very necessary to start with determining how AirtelTigoapply risk reduction strategy for its operational performance. The score of strongly agree and agree were considered to present the variable that is highlyapplied equivalent to a mean score of 3.5 to 5.0 on the continuous Likert scale. The scores of moderate applicable were taken to stand form of variable that has moderate application equivalent to 2.5 to 3.5 on the continuous Likertscale. The score of both low and not sure were considered to stand for variables of low application and not sure equivalent to 0.24 on continuous Likert. The standard deviation of $>0.9$ implies a significant variation on application of variables 
Table 4. 8 Risk Reduction Strategies used by Airtel-Tigo

\begin{tabular}{|c|c|c|c|c|c|c|c|c|c|c|c|c|c|}
\hline & \multicolumn{2}{|c|}{$\begin{array}{l}\text { Strongly } \\
\text { Disagree }\end{array}$} & \multicolumn{2}{|c|}{ Disagree } & \multicolumn{2}{|c|}{ Not Sure } & \multicolumn{2}{|c|}{ Agree } & \multicolumn{3}{|c|}{ Strongly Agree } & \multicolumn{2}{|l|}{ Total } \\
\hline & $\mathrm{N}$ & $\%$ & $\mathrm{~N}$ & $\%$ & $\mathrm{~N}$ & $\%$ & $\mathrm{~N}$ & $\%$ & $\mathrm{~N}$ & $\%$ & $\mathrm{~N}$ & Mean & Std \\
\hline $\begin{array}{l}\text { Culture evaluation after } \\
\text { merging }\end{array}$ & 3 & 3.3 & 18 & 19.8 & 27 & 29.7 & 39 & 42.9 & 4 & 4.4 & 91 & 3.25 & .938 \\
\hline Retention strategy & 9 & 9.9 & 5 & 5.5 & 30 & 33.0 & 38 & 41.8 & 9 & 9.9 & 91 & 3.36 & .069 \\
\hline Critical employee selected & 10 & 11.0 & 5 & 5.5 & 27 & 29.7 & 36 & 39.6 & 13 & 14.3 & 91 & 3.40 & 1.14 \\
\hline $\begin{array}{l}\text { Research for Customer } \\
\text { feedback }\end{array}$ & 5 & 5.5 & 11 & 12.1 & 23 & 25.3 & 37 & 40.7 & 15 & 16.5 & 91 & 3.50 & .078 \\
\hline
\end{tabular}

Source: Primary data (2021)

Table 4.8 examined risk reduction strategy that Airtel employed during the merger. The finding showed that $39(42.9 \%)$ agreed that a cultural evaluation of the two companies was done while a mean of 3.25 showed that majority were not sure. Table 4.6 is a follow-up analysis to find out if any response was different by those who worked with Tigo and present during the merger and acquisition period.

Airtel created a retention strategy for Tigo staff according to $38(41.8 \%)$. The general response on whether critical staff were maintained after the merger was agreement. Asked whether a research on customers to get their feedback was conducted by Airtel during the merger, 37(40.7\%). In general Airtel employed a risk reduction strategy in which

\begin{tabular}{llrrr}
\hline & & Flexibility & Product Quality & Customer Trust \\
\hline Culuture Evaluation & Pearson Correlation & $.231^{* * *}$ & $.159^{* *}$ & $.174^{* *}$ \\
& Sign.(2-tailed) & .006 & .043 & .014 \\
& $\mathrm{~N}$ & 91 & 91 & 91 \\
\multirow{2}{*}{ Retention Strategy } & & $.274^{* *}$ & $.187^{* *}$ & $324^{* *}$ \\
& Pearson Correlation & 0.039 & 0.035 & 0.032 \\
& Sig.(2-tailed) & 91 & 91 & 91 \\
Critical Employee Selected & $\mathrm{N}$ & $.854^{* *}$ & $.873^{* *}$ & $.750^{* *}$ \\
& Pearson Correlation & 0.018 & 0.035 & 0.036 \\
& Sig.(2-tailed) & 91 & 91 & 91 \\
Research for Customer Feedback & $\mathrm{N}$ & $.878^{* *}$ & $863^{* *}$ & $.864^{* *}$ \\
& Pearson Correlation & 0.034 & 0.017 & 0.038 \\
& Sig.(2-tailed) & 91 & 91 & 91 \\
\hline
\end{tabular}

*Correlation is significant at the $\mathbf{0 . 0 0 5}$ level

Source: Primary Data (2021)

The study proposes that in Rwandan telecommunication sector there is a significant application and using risk reduction strategies that critical Tigo staff and retention strategy was employed though there was no agreement on whether the culture of the two companies was evaluated to find out any risks it.

The researcher contrasted previous empirical studies carried out on merger and acquisitions strategies and operational performance. In this regards in order to have a good knowledge on the application ofstrategies in Rwandan telecommunication sector, the following idea emanate from the study. This indicates application of risk reduction strategy include culture evaluation, retention strategy, critical employee selected and research for customer feedback. 
overall employee turnover increases following M\&As, a more granular analysis shows that the effect is focused on employees who would not be typically considered high-human capital individuals: relatively young, with short job tenure and low income, albeit with relatively high educational level. This research indicated that survey results was in $\mathrm{p}=0.006$ ), culture evaluation and product quality $(\mathrm{r}=.159 * *, \mathrm{p}=0.043$, culture evaluation and customer trust $(\mathrm{r}=.174 * *=0.014)$. Results demonstrated that a positive correlation between retention strategy and flexibility $(\mathrm{r}=.274 * *, \mathrm{p}=0.039)$, retention strategy and product quality $(\mathrm{r}=.187, \mathrm{p}=0.035)$ retention strategy and customer trust $(\mathrm{r}=.324, \mathrm{p}=0.032)$ line with elements in with the application of risk reduction in terms of culture evaluation, retention strategy, critical employee selected and research for customer feedback

As reflected in Table 4.9, a positive correlation was found between culture evaluation and flexibility $(\mathrm{r}=231 * *$,

The researcher performed a multilinearregression in order to evaluate the effects of independent variablemerger and acquisition (culture evaluation, retention strategy, critical employee selected, and research for customer feedback) on the dependent variable operational performance of telecommunication industry (flexibility, product quality and customer trust).

Table 4.10 Regression of Coefficients

\begin{tabular}{|c|c|c|c|c|c|c|}
\hline \multirow[b]{2}{*}{ Model } & & \multicolumn{2}{|c|}{ Unstandardized Coefficients } & \multirow{2}{*}{$\begin{array}{c}\begin{array}{c}\text { Standardized } \\
\text { Coefficients }\end{array} \\
\text { Beta }\end{array}$} & \multirow[b]{2}{*}{$\mathrm{T}$} & \multirow[b]{2}{*}{ Sig. } \\
\hline & & B & Std.Error & & & \\
\hline \multirow[t]{5}{*}{1} & (Constant) & .568 & .052 & & 11.006 & .000 \\
\hline & Culture Evaluation & .067 & .021 & .091 & 3.124 & .002 \\
\hline & Retention Strategy & .139 & .023 & .192 & 6.163 & .000 \\
\hline & Critical Employee Selected & .240 & .034 & .365 & 7.118 & .000 \\
\hline & $\begin{array}{l}\text { Research for Customer } \\
\text { Feedback }\end{array}$ & .234 & .056 & .322 & 4.168 & .000 \\
\hline
\end{tabular}

a.Dependent Variables: Operational Performance

\section{Source: Primary Data (2021)}

The regression model in Table 4.10 indicated that $\mathrm{Y}=568+0.091 \mathrm{X}_{1}+0.192 \mathrm{X}_{2}+0.365 \mathrm{X}_{3}+0.322 \mathrm{X}_{4}$ where, $\mathrm{Y}$ is organization performance, $\mathrm{X}_{1}$ is culture evaluation, $\mathrm{X}_{2}$ retention strategy, $\mathrm{X}_{3}$ is critical employee selected and $\mathrm{X}_{4}$ is research for customer feedback. The regression model given a statistical follow up through that the research assessed the effect of $\mathrm{X}$ in operational performance.

A unit variation in market share would emanated from 0.091 in culture evaluation when all other independent variables were decreased to zero. A unit ofchange in operational performance would come from 0.192 in retentionstrategy when all other independent are constant to zero. Hence, a unit adjustment in operational performance is resulting in0.365 in critical employee selected if other indicators remained constant. Finally, a unit change in operational performance would result in 0.322 on research for customer feedback when other indicators are constant to zero. This denotes that all independent variables affect dependent variable.

\section{Conclusions}

Finding showed that $42.9 \%$ agreed that a cultural evaluation of the two companies was done while a mean of 3.25 showed that majority were not sure. Airtel created a retention strategy for Tigo staff according to $41.8 \%$. The general response on whether critical staff were maintained after the merger was agreement. In general Airtel employed a risk reduction strategy in which critical Tigo staff and retention strategy was employed though there was no agreement on whether the culture of the two companies was evaluated to find out any risks it. The study indicates application of risk reduction strategy include culture evaluation, retention strategy, critical employee selected and research for customer feedback.The study revealed that relationship are positively correlated given that the $\mathrm{p}$ value was < 0.005 proposing than an enhanced in merger and acquisition lead to operational performance in telecommunication sector. The regression model show that a unit variation in market share would emanated from 0.091 in culture evaluation when all other independent variables were decreased to zero. A unit of change in operational performance would 
come from 0.192 in retention strategy when all other independent are constant

\section{Acknowledgments}

I wish to acknowledge Dr.NjengaGitahi $\operatorname{Samson}(\mathrm{PhD})$ for his contribution to this work from

\section{Reference}

[1] Boukari, M. N., \& Xiaofang, C. (2014). The Impact of Mergers and Acquisition on the financial performance of West African Banks: A case study of some selected commercial banks. International Journal of Education and Research (Vol. 2).

[2] Bruno, M., \& Broderick, S. (2014). Mergers and acquisitions may be on upswing.

[3] Chiang, I.-C. A., Jhangiani, R. S., \& Price, P. C. (2015, October). Correlational Research. BCcampus.

[4] Hitt, M., King, D., Krishnan, H., Makri, M., Schijven, M., Shimizu, K., \& Zhu, H. (2012). Creating Value Through Mergers and Acquisitions. In The Handbook of Mergers and Acquisitions (pp. 71-113). https://doi.org/10.1093/acprof:oso/9780199 601462.003.0004

[5] Kamau, C. N. (2014). Effect of Internal Controls on the Financial Performance of Manufacturing Firms in Kenya. Nairobi.

[6] Kim, J.-Y. (Jay), Haleblian, J. (John), \& Finkelstein, S. (2011). When Firms Are Desperate to Grow via Acquisition: The Effect of Growth Patterns and Acquisition Experience on Acquisition Premiums. Administrative Science Quarterly, 56(1), 26-60.

[7] Leepsa, nm, \& Mishra, C. (2016). Theory and Practice of Mergers and Acquisitions: Empirical Evidence from Indian Cases. IIMS Journal of Management Science, 7, $179 . \quad$ https://doi.org/10.5958/0976173X.2016.00016.6

[8] Moore, T. (2011). Does Market Structure Matter on Banks ' Profitability and Stability? Emerging versus Advanced Economies Does Market Structure Matter on Bank s' Profitability and, (11).

[9] Ofori, G. (2000). Challenges of Construction Industries in Developing Countries: Lessons from Various Countries. Citeseerx.Ist.Psu.Edu, 15-17. https://doi.org/10.1.1.198.2916

\section{ISSN 2455-6378}

the beginning up to its completion. I extend my acknowledgement to the authorities of Airtel Rwanda for their support and cooperation during this study.

[10] Ondieki, J. G., \& Mungai, J. N. (2015). The Effect of Mergers and Acquisitions on Financial Performance of Banks (A Survey of Commercial Banks in Kenya). INTERNATIONAL JOURNAL OF INNOVATIVE RESEARCH \& DEVELOPMENT (Vol. 4).

[11] Sciriha, I., \& Debono, M. (2017). The Effects and Management of Cultural Differences During the Integration Process of Mergers and Acquisitions. Journal of Media Critiques, 3, 31-50. https://doi.org/10.17349/jmc117402

[12] Shukla, A., \& Gekara, M. (2008). Effects of Multinational Mergers and Acquisitions on Shareholders' Wealth and Corporate Performance. The IUP Journal of Accounting Research and Auidt Practices, IX, 44-62.

[13] Strydom, H. (2015). a field trip as part of the social work research module Herman Strydom, Marie Ubbink, 50(4).

[14] Teixeira, R., Koufteros, X., Xiaosong, D., \& Peng, X. (2012). organizational structure, integration, and manufacturing performance: a conceptual model and propositions. Journal of Operation and Supply Chain Management, 5. https://doi.org/10.12660/joscmv5n1p70-81

[15] Voss, C., Åhlström, P., \& Blackmon, K. (1997). Benchmarking and Operational Performance: Some Empirical Results. Benchmarking for Quality Management \& Technology, 4, 273-285. https://doi.org/10.1108/1463577971019511 3

[16] Weber, Y. (2015). Development and Training at Mergers and Acquisitions. Procedia - Social and Behavioral Sciences, 209, 254-260. https://doi.org/10.1016/j.sbspro.2015.11.22 9 